\title{
Malignant Intestinal Neoplasm
}

National Cancer Institute

\section{Source}

National Cancer Institute. Malignant Intestinal Neoplasm. NCI Thesaurus. Code C4572.

A primary or metastatic malignant neoplasm involving the small intestine, large intestine,

or both. Representative examples are carcinomas, lymphomas, and sarcomas. 